\title{
Halitosis-An Update
}

\author{
Rupali Kalsi ${ }^{1}$, Mohit Kumar Mathur ${ }^{2}$, Nishant Singh Gill ${ }^{3}$, Poonam Dutt ${ }^{4}$ \\ ${ }^{l}$ (Reader, Department Of Periodontics, Shree Bankey Bihari Dental College, Ghaziabad, U.P, India) \\ ${ }^{2}$ (Assistant Professor, Department Of General Surgery, School Of Medical Sciences \& Research, \\ Sharda University, Greater Noida, U.P, India ) \\ 3 (Intern, Sardar Patel Medical College, Bikaner, Rajasthan, India) \\ ${ }^{4}$ (Professor \& Head, Dept .Of Periodontics, Shree Bankey Bihari Dental College, Ghaziabad, India)
}

\begin{abstract}
Bad breath can be detrimental to one's self-image and confidence causing social, emotional, and psychological anxiety. With the majority of breath problems having an oral origin, the dental office is the most logical place for patients to seek treatment. The etiology of halitosis is related to release of odiferous compounds like volatile sulphur compounds in the exhaled air. This article reviews the etio-pathogenesis and patho-physiology of halitosis (oral malodor) , various classification systems, methods of detection and its management.
\end{abstract}

Keywords: Halitosis, Oral malodor, Periodontitis, Review, Volatile sulphur compounds.

\section{Introduction}

Halitosis is derived from the Latin word "Halitasia" meaning bad breath and the Greek word "Osis" meaning disease or condition.Halitosis is an unpleasant or offensive odour emanating from the oral cavity, leading to discomfort and psychosocial embarrassment.Halitosis is estimated to be the third most frequent reason for seeking dental aid, following tooth decay and periodontal disease. ${ }^{1}$

Various Terminologies/ Classifications Related To Halitosis ${ }^{2}$

\begin{tabular}{|c|l|l|}
\hline Terms Used & \multicolumn{2}{|c|}{ Definition } \\
\hline Halitosis & Any Disagreeable Odor Of Expired Air, Regardless Of Origin \\
\hline Bad Breath & Lay Term For Halitosis \\
\hline Genuine Halitosis & Where Breath Malodor Can Be Verified Objectively \\
\hline & $\begin{array}{l}\text { Physiologic Halitosis, Also } \\
\text { Termed Transient Halitosis }\end{array}$ & Pathologic Halitosis \\
\hline & E.G. Morning Breath & $\begin{array}{l}\text { Subclassified Into } \\
\text { Oral Malodor (Foetor Oris Foetor Ex } \\
\text { Oris) And } \\
\text { •Extra-Oral }\end{array}$ \\
\hline Pseudo-Halitosis & No Objective Evidence Of Malodor, But The Patient Thinks They Have It \\
\hline Halitophobia & $\begin{array}{c}\text { The Patient Persists In Believing They Have Halitosis Despite Firm Evidence } \\
\text { For The Absence Of Objective Evidence }\end{array}$ \\
\hline
\end{tabular}

\section{ADA classification based on the etiological pathways involved}

- Extrinsic pathways - Tobacco, alcohol and foods like onions garlic and certain spices.

- Intrinsic pathways -

- Oral origin $(90 \%)$

- Systemic origin $(10 \%)$

Classification based on the origin of halitosis (Dominic 1982) $)^{3}$

1. Due to local factors of Pathological origin

2. Due to local factors of Non-pathological origin

3. Due to systemic factors of Pathological origin

4. Due to systemic factors of Non-pathological origin

5. Due to systemic administration of Drugs and

6. Due to xerostomia.

\section{Epidemology}

There are few studies evaluating the prevalence of oral malodor in the general population, with reported rates ranging from $22 \%$ to more than $50 \%$. In addition, approximately $50 \%$ of adults and elderly individuals emit socially unacceptable breath, related to physiological causes, upon arising in the 
morning. ${ }^{4}$ Moreover, there are no universally accepted standard criteria, objective or subjective, that define halitosis in a patient. ${ }^{5}$

A study performed by Miyazaki et al. ${ }^{5}$ examining oral malodor in 2,672 individuals aged 18 to 64 years observed that there were no significant differences in the VSC between males and females in any age group. In each age group, the measured values of oral malodor were highest in the late morning group $(58.6 / \mathrm{ppb}$ in average), followed by the late afternoon group $(52.1 / \mathrm{ppb})$, while lowest values were shown in the early afternoon group (39.4/ ppb). Significant correlation was observed only between VSC values and periodontal conditions and tongue coating status.

III. Odiferous Compounds

\begin{tabular}{|l|l|}
\hline Volatile Sulfur Compounds & Methyl Mercaptan, Hydrogen Sulfide Dimethyl Sulfide \\
\hline Diamines & Cadaverine,Putrescine \\
\hline Short-Chain Fatty Acids & Butyric Acid,Valericacid,Propionic Acid \\
\hline Indoles & Indole, Methyl-Indole (Skatole) \\
\hline
\end{tabular}

\section{Pathophysiology Of Oral Malodor}

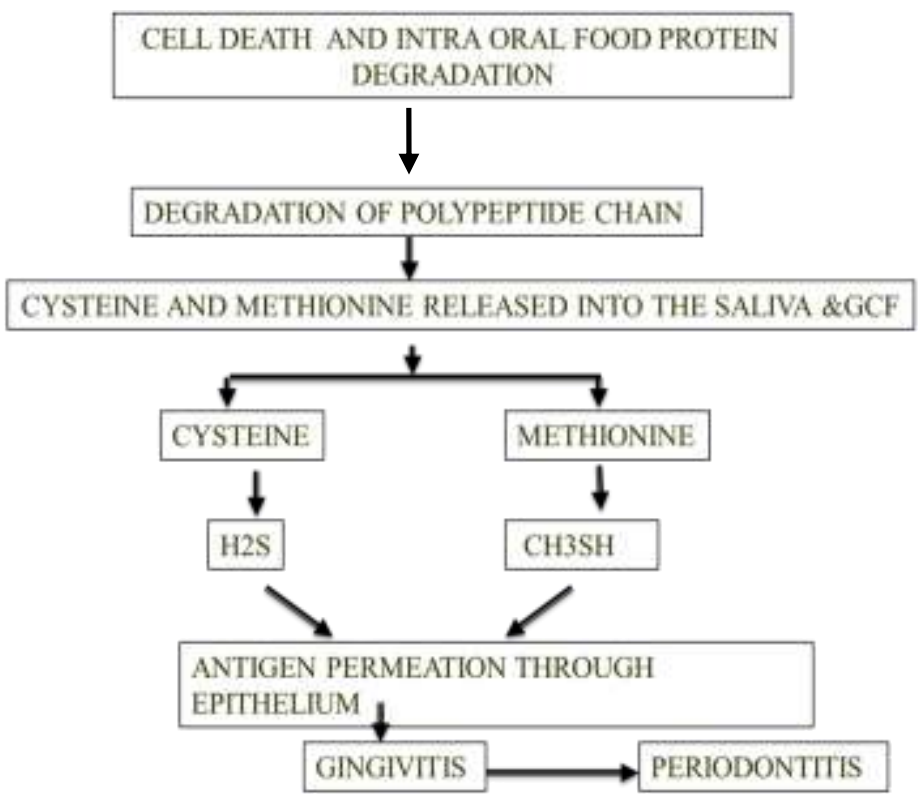

Relationship Between Vsc's And Periodontitis ${ }^{8,9,10,11}$

- VSC's alter permeability of gingival tissues (J.E \&O.E) to LPS .

- Sulfides may annihilate the opsonization of C3bi and affect its ability to fight bacteriaThey modulate function of fibroblast

- VSC's increase secretion of PGE2 \& collagenase

- VSC increase in deep pockets

- Tongue coating 6 times more in periodontitis patients

\section{Diagnosis}

A saying "Listen to the patient and he will tell you the diagnosis". This is very true for patients with breath odor complaints.

The primary measurement methods are

1. Organoleptic measurement

2. Gas chromatography

3. Alternative methods- BANA test, salivary incubation test, quantifying $\beta$-galactosidase activity, ammonia monitoring, the ninhydrin method and the PCR, have yet to be fully established

Apart from this self assessment method can also be done.

\section{Organoleptic Assessment}


The clinician sniffs the air exhaled from the mouth and nose and subjectively defines the presence or absence of malodor. This should be performed by two or more different examiners and both the human subject and the examiners should follow some instructions in order to obtain more reliable results

It is advisable that the patient abstains from eating odiferous foods for $48 \mathrm{~h}$ before the assessment and that both the patient and the examiner refrain from drinking coffee, tea or juice, smoking and using scented cosmetics before the assessment. ${ }^{12}$

Volatile sulfur compounds can also be detected by HALIMETER (Interscan Corp., Chatsworth, CA), a portable sulfide monitor. This is an electronic device that aspirates the air of the mouth or expired air through a straw and analyzes the concentration of hydrogen sulfide and $\mathrm{CH}_{3} \mathrm{SH}$. However, this machine cannot differentiate between the different types of sulfides and cannot detect other classes of volatile compounds. ${ }^{13}$.

\section{Gas Chromatography}

It runs with a Mass Spectrometry Detector. It used for differentiating and quantifying the VSC and also distinguish other classes of compound Drawbacks of traditional laboratory methods are -cumbersome, need inert column carrier gas (gas cylinders of nitrogen or helium) and require technicians with adequate training.

Recently, trailblazing research was performed by van den Velde et al..$^{14,15}$ with gas chromatography-mass spectrometry as a tool for differential diagnosis of halitosis, with the possibility to detect extra-oral causes, which often remain undetected unless characterized by a specific smell.

\section{Secondary Tests Associating Measurements of Oral Malodor}

Detection of likely causative bacteria and / or microbial enzymatic activity fall outside the routine clinical assessment of halitosis.Examination of the oral flora, can be done using the BANA test or dark-field microscopy Assay for the major glycosidic enzyme-( $\beta$-galactosidase) in saliva, which deglycosylates oral mucins, leading to their subsequent proteolysis and putrefaction, may also be useful. ${ }^{16}$

If no malodor can be found during the initial examination, the assessment for halitosis should be repeated on two or three different days.

$>$ the patient can be considered to be affected by imaginary (pseudo-halitosis)

$>$ diagnosis that can be supported by established questionnaires

\section{Diamond probe:}

Sensors are integrated into the periodontal probe. Probe is placed directly into the periodontal pocket or tongue. It has an electrical control unit and a disposable sensor tip that combines a standard Michigan 0 dental probe with a sulphide sensor which responds to the sulfides present in the periodontal pocket. ${ }^{17}$

\section{Treatment Of Halitosis}

The treatment and management of Halitois can be broadly classified into mechanical microbiological load reduction, use of chemotherapeutic agents (in office or at home) or a combined approach. ${ }^{2}$

\begin{tabular}{|c|c|c|c|}
\hline Classification & $\begin{array}{l}\text { Treatment } \\
\text { Needs }\end{array}$ & Description & Treatment needs \\
\hline $\begin{array}{l}\text { 1. Genuine } \\
\text { Halitosis }\end{array}$ & & $\begin{array}{l}\text { Obvious malodor, with } \\
\text { intensity beyond socially } \\
\text { acceptable level is perceived. }\end{array}$ & \\
\hline $\begin{array}{l}\text { a. Physiologic } \\
\text { halitosis }\end{array}$ & $\mathrm{TN}-1$ & $\begin{array}{l}\text { Malodor arises through } \\
\text { putrefactive processes within } \\
\text { the oral cavity. Neither a } \\
\text { specific disease nor a } \\
\text { pathologic condition that } \\
\text { could cause halitosis is found. } \\
\text { Origin is mainly the } \\
\text { dorsoposterior region of the } \\
\text { tongue. }\end{array}$ & $\begin{array}{l}\text { Explanation of halitosis } \\
\text { and instructions for oral } \\
\text { hygiene (support and } \\
\text { reinforcement of a } \\
\text { patient's own self-care } \\
\text { for further improvement } \\
\text { of their oral hygiene) }\end{array}$ \\
\hline $\begin{array}{l}\text { b. Pathologic } \\
\text { halitosis }\end{array}$ & & & \\
\hline i. Oral & $\mathrm{TN}-2$ & $\begin{array}{l}\text { Halitosis caused by disease, } \\
\text { pathologic condition or } \\
\text { malfunction of oral tissues } \\
\text { (tongue coating, modified by } \\
\text { pathologic condition like } \\
\text { xerostomia) }\end{array}$ & $\begin{array}{l}\text { Oral prophylaxis, } \\
\text { professional cleaning and } \\
\text { treatment for oral } \\
\text { diseases, especially } \\
\text { periodontal diseases }\end{array}$ \\
\hline ii. Extra-oral & $\mathrm{TN}-3$ & $\begin{array}{l}\text { Malodor originates from } \\
\text { nasal, paranasal and/or } \\
\text { laryngeal regions, pulmonary } \\
\text { tract or upper digestive tract. } \\
\text { Odor is blood-borne and }\end{array}$ & $\begin{array}{l}\text { Referral to a physician or } \\
\text { a medical specialist }\end{array}$ \\
\hline
\end{tabular}




\begin{tabular}{|c|c|c|c|}
\hline & & $\begin{array}{l}\text { emitted via the lungs (e.g. } \\
\text { diabetes mellitus, hepatic } \\
\text { cirrhosis, uremia, internal } \\
\text { bleeding }\end{array}$ & \\
\hline $\begin{array}{l}\text { 2. Pseudo- } \\
\text { halitosis }\end{array}$ & $\mathrm{TN}-4$ & $\begin{array}{l}\text { Obvious malodor is not } \\
\text { perceived by others, although } \\
\text { the patient stubbornly } \\
\text { complains of its existence. } \\
\text { Condition is improved by } \\
\text { counseling and simple oral } \\
\text { hygiene measures. }\end{array}$ & $\begin{array}{lr}\text { Explanation } & \text { of } \\
\text { examination data, further } \\
\text { professional instruction, } \\
\text { education } \\
\text { reassurance }\end{array}$ \\
\hline 3. Halitophobia & $\mathrm{TN}-5$ & $\begin{array}{l}\text { After treatment for genuine } \\
\text { halitosis or pseudo-halitosis, } \\
\text { the patient persists in } \\
\text { believing that he/ } \\
\text { she has halitosis. No physical } \\
\text { or social evidence exists to } \\
\text { suggest that halitosis is } \\
\text { present. }\end{array}$ & $\begin{array}{l}\text { Referral to a clinical } \\
\text { psychologist, } \\
\text { psychiatrist or other } \\
\text { psychology specialist }\end{array}$ \\
\hline
\end{tabular}

*TN-1 Is Applicable To All Cases Requiring TN-2 Through TN-5

\section{Mechanical Reduction of Intraoral Nutrients and Microorganisms}

The dorsal surface of most tongues usually has significant observable debris. Brushing studies indicate that the tongue was the main source of $\mathrm{CH} 3 \mathrm{SH}$ and H2S. Tongue cleaning has been advocated to reduce the amount of tongue coating and the bacterial load on the tongue surface. People with halitosis are well-advised to repeat the tongue cleaning procedures several times during the day. ${ }^{18}$

\section{Chemical Reduction of Oral Microbial load}

Mouth rinsing is a common oral hygiene practice dating back to ancient times. The active ingredient in oral rinses is usually antimicrobial agents such as Chlorhexidine (CHX), essential oils, chlorine dioxide, hydrogen peroxide and triclosan.

CHX can be used alone CHX-Alc $(0.2 \%)$ or in combination with other formulation like CHX-NaF $(0.12 \% \mathrm{CHX}+0.05 \% \mathrm{NaF})$ or Halita/CHX-CPC-Zn $(0.05 \% \mathrm{CHX}+0.05 \% \mathrm{CPC}+0.14 \% \mathrm{Zn}$ lactate $)$ or $\mathrm{AmF} / \mathrm{SnF} 2$ mouth rinse. All these formulations result in significant reduction in microbial load of tongue and saliva. Essential oils like Listerine can be used as mouthwashes. Plaque reductions of 20-35\% and gingivitis reductions of $25-35 \%$ have been reported. ${ }^{19}$

\section{Two-Phase Oil: Water Mouthrinse}

These mouthrinses are highly effective in reducing bad breath parameters. A twice daily rinse showed reductions in both VSC and organoleptic rating. Triclosan (2,4,4-trichloro-2-hydroxy-diphenyl ether) is a lipidsoluble antibacterial agent that has be particularly effective in reducing VSC, oral bacteria and oral malodour. ${ }^{6}$

\section{Probiotics and Halitosis}

Probiotics are living microorganisms which upon ingestion in sufficient numbers exert health benefits beyond basic nutrition. It has been reported that administration of Weissella Cibaria, reduces levels of volatile sulfide compounds produced by Fusobacterium nucleatum: the effect could be due to hydrogen peroxide production by $W$. cibaria causing $F$. nucleatum inhibition. ${ }^{20}$ Streptococcus salivarius also suppress volatile sulfide effects, by competing for colonization areas with volatile sulfide-producing species. ${ }^{21}$

\section{Conclusion}

Breath odor has important socio-economic consequences and can reveal important diseases. Thus, a proper diagnosis and determination of the etiology allows initiation of the proper treatment.

\section{References}

[1]. Loesche, WJ; Kazor, C . "Microbiology and treatment of halitosis". Periodontology 2000 .2002;28:256-79.

[2]. Miyazaki H, Arao M, Okamura K, Kawaguchi Y, Toyofuku A, Hoshi K, YaegakiK.Tentative classification of halitosis and its treatment needs.Niigata Dent 1999 J 32: 7-11

[3]. Lu, D. Halitosis: an etiologic classification, a treatment approach, and prevention. Oral Surgery, Oral Medicine, And Oral Pathology 1982; 54(5): 521-526

[4]. Rosenberg M. Bad breath: research perspectives. Ramat Aviv: Ramot Publishing-Tel Aviv University Press; 1997.

[5]. Miyazaki H, Sakao S, Katoh Y, Takehara T. Correlation between volatile sulphur compounds and certain oral health measurements in the general population. J Periodontol. 1995;66(8):679-84.

[6]. Porter SR, Scully C. Oralmalodour (halitosis). BMJ. 2006 Sep 23;333(7569):632-5

[7]. Reingewirtz Y, Girault O, Reingewirtz N, Senger B, Tenenbaum H Mechanical effects and volatile sulfur compound-reducing effects of chewing gums: comparison between test and base gums and a control group. Quintessence Int 1999;30:319-323. 
[8]. Granlund-Edstedt M, Johansson E, Claesson R, Carlsson J. Effect of sulfideions on complementfactorC3. Infect Immun. 1991 Feb;59(2):696-9.

[9]. Ratcliff PA, Johnson PW. The relationship between oral malodor, gingivitis and periodontitis. A review. J Periodontol. 1999;70:485-489.

[10]. Coli JM, Tonzetich J. Characterization of volatile sulphur compounds production at individual gingival crevicular sites in humans. J Clin Dent.1992;3(4):97-103.

[11]. Yaegaki K, Sanada K. Volatile sulphur-compounds in mouth air from clinically healthy subjects and patients with periodontal disease. J Periodont Res. 1992;27 4 Pt 1:233-238

[12]. Snel J, Burgering M, SmitB Volatile sulphur compounds in morning breath of human volunteers. Arch Oral Biol. 2011;56 1:29-34

[13]. Alagirisamy N, Hardas SS, Jayaraman S Novel colorimetric sensor for oral malodour. Anal ChimActa. 2010 Feb 19;661(1):97-102

[14]. Van den Velde S, Quirynen M, Van Hee P. Halitosis associated volatiles in breath of healthy subjects. J Chromatogr B AnalytTechnol Biomed Life Sci. 2007;853 1/2:54-61.

[15]. Van den Velde S, Nevens F, Van Hee P. GC-MS analysis of breath odor compounds in liver patients. J Chromatogr B AnalytTechnol Biomed Life Sci. 2008;875 2:344-348.

[16]. Sterer N, Greenstein RB, Rosenberg M.Beta-galactosidaseactivity in saliva is associated with oralmalodor. J Dent Res. 2002 Mar;81(3):182-5

[17]. Zhou H, McCombs GB, Darby ML, MorinakK.SulphurBy Product: The relationship between volatile sulphur compounds and dental plaque-induced gingivitis.JContemp Dent Pract. 2004 May 15;5(2):27-39.

[18]. Quirynen M, Avontroodt P, Soers C, Soers C, Zhao H, Pauwels M. Impact of tongue cleansers on microbial load and taste.JClinPeriodontol 2004;31:506-10.

[19]. Newman MG, Takei HH, Carranza FA. Clinical Periodontology. 10th ed: Saunders; 2009:330-41

[20]. Kang MS, Kim BG, Chung J, Lee HC, Oh JS. Inhibitory effect of Weissellacibaria isolates on the production of volatile sulphur compounds.JClinPeriodontol. 2006;33:226-32.

[21]. Burton JP, Chilcott CN, Tagg JR. The rationale and potential for the reduction of oral malodour using Streptococcus salivarius probiotics. Oral Dis. 2005;11Suppl 1:29-31. 